\title{
Assessing the Use of Recovery Model for Medication Adherence on Mental Health Patients - A Case Study Analysis
}

\author{
Victor ETU Tanyi BSc RN \\ Dissertation presented for an Award ofBSc in Nursing.
}

\begin{abstract}
This integrative review is aimed at identifying the experiences of mental health patients as well as the perception of health care professionals caring for them with regard to understanding medication adherence and overall treatment using the Recovery Model.The rationale is based on placing increasing emphasis on the Recovery Model; requiring the health care system to provide care based on individual needs. The current trend is for care to seek to promote empowerment and social inclusion.The review further strives to provide insight into how the service users experience care and support in order to assess the extent at which the elements of recovery are embedded in mental health practice.Following extensive searching of the data bases and library resources available and application of the predetermined inclusion /exclusion criteria, fifteen published articles and ten policy guidelines on recovery were reviewed for this work.

Two themes emerged:

A. The elements of client centred care, (with the sub themes including hope, social inclusion, empowerment and shared decision making)

$B$. The policies guiding recovery.

The findings of the review were geared towards assessing the clients' and health care providers' perspective on recovery. Happily, both patients and health professionals share the opinion that the Recovery Model is significant in enhancing treatment, including medication adherence. There may be some variation as to how professionals and patients view recovery in terms application of the Recovery Model but these differences are not within the scope of this review.
\end{abstract}

\subsection{Case Study}

\section{Introduction}

The reasons for choosing this topic are derived from my experience in placement, on the patients who were described as noncompliant and the perception of the nurses towards these patients. Non-compliances, according to the nurses, will refer to those who did not want to take any medication voluntarily, would hide, spit out or throw their medication in a bin after leaving the medication room, and also those who may fail to take their medication as prescribed. There was a specific case of a 50-year-old lady with depression that sparked my interest in the issues related to medication adherence. She routinely felt reluctant to come for her medication and, whenever she turned up, would choose which medication to take and often hide some in a paper napkin in the palm of her hand. She was often seen the last to save time and had been labeled as "bad". The nurses were often stressed and found her behavior frustrating. During handovers and in their notes, they continued to describe the patient as noncompliant.

No action plan was made to address the lady's poor adherence and such a need was not incorporated into the care plan. As a student nurse, I found this conflicting with the client- centered approach and began to raise questions as to whether, in a practice situation, recovery could be a tool to support and develop a much better therapeutic relationship with this lady and also to help her to adhere to her medication.

In this case study analysis, the researcher will, be carrying out a systematic review of the literature referencing recovery in relation to medication adherence and overall treatment of patients with mental health disorders.

\subsection{Background}

According to Delamater (2006), adherence is defined as the "Active, voluntary, and collaborative involvement of the patient in a mutually acceptable course of behaviour; to produce a therapeutic result." This definition is similar to that of Ho et al.(2009), defining adherence as a reflection of patient's choice of action.Treatment goals and the medical regimen adopted to achieve those goals are mutual decisions, made with the patient and the health provider(s) working together. Simply put,DiMatteo et al. (2014) define adherence as the "Extent to which the health professional's agreed recommendations matchesthe patient's action".

These definitionsimply that the patient has a choice and that both patients and health providers mutually establish treatment goals and the medical regimen. Adherence, therefore, presumes "agreement about the proposedmedication, between the prescriber and the person takingthe medicine, emphasizing the importance of shared decision- making" (NICE Guideline, 2009). 
It is not unusual for clinicians to describe a client as non-adherent, difficult, and showing lack of insight when medication is not taken as prescribed (Gould and Mitty, 2010). In this context, nonadherence is regarded as bad behavior and the health professionals may fail to recognize reasons for poor adherence.To them, adherence means the patient following the clinician's opinion without question; having no say in his/her treatment (Gould and Mitty, 2010). According to Bollini et al. (2004) and Gould and Mitty (2010),medical professionals do not just underestimate the decisions and feelings of patients facing stress issues but they also neglect to question the patient as to the reasons underlying issues of adherence.

This method of treatment guarantees the alleviation of symptoms but the patient may continue to be dependent on the health system and may relapse soon after personal support is withdrawn. There is also the concern that the patient may not appreciate the value of the medication and cease to take it. Conversely, Deegan and Drake (2006) document cases where the patient may become too dependent on the medication. Long-term side effects may then take a toll on the quality of his or herlife and the patient,rather than seeking alternative treatment, instead turns to other addictions that are more accessible.

The concept of recovery is much wider than simply remission of clinical signs and symptoms and may not include a traditional cure as the end point (Roberts and Wolfson, 2004).

The basic themes that underpin recovery are: living well despite the limitations of illness, participating fully in community, autonomy, self-management and responsibility, personal growth, person-centred services, resilience, hope, and empowerment (Irish Mental Health Commission 2005). Each service user will understand and express a sense of recovery in different ways. To some, it may mean finding a way to manage themselves within society, despite mental illness whilefor others,recovery may be about the remission of symptoms.

The recovery model requires that the patient is empowered to bear some responsibility for his treatment and thusenabled to understand the balance between the benefits of adhering to a medication and the risk of side effects.

Evaluating medication adherence and the relationship between the patient and the healthcare professional, the level of trust and knowledge involved, also remains a concern for further review. The healthcare system can contribute not only towards building higher levels of self-esteem and hope for the patient but should also engender better awareness and accountability towards understanding treatment in the form of medication. Stein et al. (2013) suggest the relationship of the patient with his or her drug protocol is not an aspect of recovery that remains stagnant but in fact, with the many stages of recovery, the level and types of medications may change. Barber (2012) promotes the idea of patient advocacy at a level where they seekboth care and knowledge of the treatment from their health provider.This approach can be a powerful tool for improving self-esteem and hope of wellness. Care is placed in the hands of the patient and the level of care and trust involved with the service is redefined. This approach increases the requirement for high-quality care and also allows greaterpatient involvement. Ideally, care should be patient-centred, with the whole experience being shared openly.

Another issue of interest in this research would be how to address the level of stigma attached to those experiencing mental health issues.Chronister et al. (2013,) wrote, "Stigma has been associated with lower selfesteem, depression, feeling misunderstood and ashamed, poor medication adherence, fewer successful social interactions, reduced help seeking, worse recovery, lower quality of life, fewer job opportunities, inadequate health coverage, and fewer leased apartments."Barber(2012) corroborates these findings, stating that the shift in social environment and in how people treat each other via stigma and judgment of the self has created a pandemic of varying degrees of mental illness; all in need of medication adherence and adjusted levels of treatment strategies.

Although addressed directly here, it is worthwhile to identify some of the factors that may hinder adherence to medication.It is important to highlight specific factors that may give rise to a patient's adherence problems.A variety of problems may be involved and a multifaceted approach may be needed to customize any intervention that might be necessary (Velligan et al., 2010).

Velligan et al., (2010) confirmed that many commonly used antipsychotic drugs commonly have dilapidating and painful extrapyramidal side effects. Patients taking these drugs often havepoor insight into their level of illness. Poor adherence often results from a belief that the medications are no longer needed.The newer atypical antipsychotics may cause weight gain, sedation, and anticholinergic side effects (Stanniland and Taylor, 2000; Piparva et al., 2011). However,Marder (1998) predicts that the newer atypical agents will increase adherence, because the side effect profiles of these medications may be more appealing to patients than those of the older or typical, conventional antipsychotics.

In addition, the symptoms experienced by some patients when unwell may lead to poor adherence to medication (Kauppi et al., 2014).Grandiose delusions,for instance,can cause patients with schizophrenia to refuse treatment while paranoid delusions may cause them to fear treatment (Valenstein et al., 2004).

Patients may sometimes be sectioned under section three of theMental Health Act, 1983 (MHA)to compel them to follow a strict medication regimen. This tool, though effective, may not be sustainable as 
patients often relapse when no longer sectioned. Under the MHA, the patient's right to autonomyis compromised.Patients often feel they are medicated against their wishes.It is advisable thereforefor clinicians to explore a variety of client-centred approaches; based on a recovery model that is targeted to engaging the patient and improving adherence to the medication regimen.

\subsection{The Problem}

The underlying problem is the failure of professionals to appreciate the need to distinguish between adherence and nonadherence and not discussing the need for adherence with their patients. The safety of patients and their carers within a secured setting is of paramount importance and certainsections within the MHAmay interfere with and supersede the patient's rights to autonomy. However, irrespective of the law,compassionate intervention remains a key factor to recovery. It is much easier to reach a mutual agreement between patient and professional where both have the same goal and wish to achieve it via the same process,thus eminent that such an approach makes sense and will ultimately be more robust.

Therefore, the initial problem under consideration for a favourable, effective and efficient solution is the non-adherence of patients. However, the bigger and more toxic problem is one of ineffective treatment.This is a bad option for everyone, service providers, patients and the overall economy alike as it increases costs and use of resources to no beneficial effect. This view is in accordance with Ramdour et al. (2015) who maintains that "Given personal, social and economic sequelae of poor adherence, studies have sought to identify strategies to improve adherence."

Conn et al. (2016) also considers inappropriate medication adherence; leading to a global epidemic with an estimated cost to the health care system of $€ 25$ billion in the European Union.

In this study, the researcher has taken the initiative to apply a recovery model with the aim of developing a potential solution to these problems, both of which arise from non-adherence.

\subsection{Purpose of Research}

The purpose of this research is to prove the case that a recovery model, recommending a professional and patient partnership for the overall good, is sufficient, reliable and robust enough to compliment the efforts of the professionals and provide better results for both parties.

In addition, a structured and comprehensive literature review will be conducted to enable the researcher to critically evaluate the collected evidence and to draw conclusions and recommendations from practice that can be applied to a critical incident or case study. In this way, the researcher can use the findings of current research to help in conducting an independent case study that is targeted and linked to an area of practice.

\subsection{Research Questions}

Does the process involve both the patient and the professional by mutual consent, as well as mutual agreement,impact on treatment and adherence amongst patients with mental health issues?

Do the elements associated with the Recovery Model help patients to adhere to medication and to recover effectively and efficiently?

Does the Recovery Model help increase the overall quality of user/patient service?

Do the law and governance support the initiation, application, and usage of the Recovery Model?

\subsection{Data Search, Inclusion/Exclusion criteria/Rational}

\section{Methods}

The researcher conducted a systematic literature review to include English-language text currently published.Bryman (2015) describes systematic review as "A replicable, scientific and transparent process which in the final state will provide an audit like structure to a larger diffusion of information from experts in the subject matter. The audit aspect of the review highlights the most relevant evidence of each case and sets into place a precise and functional review of the specific evidence, study procedures utilized and recommendation from conclusions, if not detailed gaps found." Bryman (2015), further states, "It is important to chart out what the exact parameters and search terms exist for the review as this will allow the case studies to systematically fall into place for specific categories." For this review, the search is to find both studies that pertain to the healthcare professional's point of view on recovery and also to the patient's perspective on his or her journey to wellness; with respect to self-esteem and hope. Not all the elements of recovery may guarantee medication adherence or effective treatment (Jackson et al, (2014). The researcher may limit the analysis to those that are relevant and still prove the point that the elements of recovery are vital in effective treatment. The researcher thus included hope, empowerment, social aspects of recovery, and above all shared decision as inclusive criteria.

To find articles/journals relevant to the topic, the University of Derby online database,Search Library Plus was searched. This is a straightforward database that produced a variety of relevant current literature 
related. However, the researcher also included some peer-reviewed landmark publications that are outdated but serve to establish the background of the research.

For the searches, the keywords "Recovery," "Adherence," "Shared decision" "Policy"were used to scan for all the articles published in medical/mental health.Each word or set of words was searched independently, for instance,recovery/ mental health, medication adherence/mental health.This search came up with 8537results, 6507 for medication adherence mental, 2030 for shared decision making/mental. The search for policy in mentalhealth did not give the type of data the researcher needed so Google Search and books on the topic in university library were also used. Also, there were almost 38,000 results that the researcher felt were not relevant to the case study. The results of the first two searches highlighted issues of recovery in detail and were of most interest. Any articles that were not of mental health origin were excluded and 150 articles written since 2011 were selected.At this stage, the abstract of each article was carefully read to determine the relevance of the study for review and the selected publications reduced to 104. Predefined criteria for selecting the relevant data for analysis include the following: The data source should be addressing recovery and medication adherence. The study population comprises of adults with mental health issues with or without psychotic symptoms. The experiences of the consumers of psychotropic drugs were taken into account, as were the experiences of health professionals prescribing and dispensing the medication. Any government policy guiding recovery and medication adherence was incorporated into inclusive criteria. All other journals and articles that were not of mental health origin were briefly read as potential sources of inspiration but were excluded.

Most of the literature used to review the study was drawn from accredited academic journals including: Journal of Groups in Addiction \& Recovery, International Journal of Nursing Studies, Science Direct, Journal of Applied Rehabilitation Counselling, Journal of Psychiatric and Mental Health Nursing, Journal of Mental Health, American Journal of Orthopsychiatry, and Community Mental Health Journal.These Data Base sources are peered reviewed; implying that the article had been read by authorities in the field and the accuracy and appropriateness of the methodology used in the study validated and considered to be trustworthy (Burns and Grove, 2007). These articles specifically address the basic elements required such asmedication adherence and recovery in mental health, patients ' perspective on poor adherence, and nurse prescribing in mental health using the Recovery Approach.

Most of the sources cited in the research report are of recent origin.Coughlan et al. (2007) state that studies should be less than five years old if they are to be considered current. This does not imply that studies published more than five years ago are not credible. Some of the articles that are cited in this work, for instance, Valenstein et al. (2004) and Ho et al. (2009) are landmark publications. Also, the study requires that we include some government and legal policies guiding recovery, which may be relevant but are drawn from articles that are more than five years old. For reasons of convenience,publications available locally were searched manually for purposes of gaining insight into the findings, for referencing in the background of study and in structuring the research methods. Such data, except for the policies guiding recovery, were not included in the results.

In collecting the data, reviewing the findings and analysing the results, the researcher will explore any form of accredited study that is within the inclusive criteria; whether a case study, qualitative/quantitative, mixed methods, systematic review or empirical study.However,for the purpose of this study that will take into consideration patients' and clinicians' perspective, and their lived experience on mental health problems, the focus will be on case studies, cross-sectional designs and qualitative studies.

Prior research and relevant case studies will be searched, discussed and evidenced in order to prove the effectiveness and efficiency of a recovery model in helping the patients who are under consideration. Further, the researcher will look for critical cases that have been covered through different techniques like 'in-depth interviews' and 'Focus Group Discussions (FGD)' with both professionals and patients.

This may mean exploring the primary data sources, and listening to the voices of the participants whilst reviewing the literature.

(See summary Table Appendix 1: Inclusion/Exclusion criteria).

\subsection{Research Design}

In order to investigate and solve real-life problems in search of possible solutions, the case study approach is recommended.This approach enables data collection at different times and places over a period of time in a comprehensive and sustained manner and enables its effectiveness over a short time (Creswell \& Plano Clark, 2007). No research method is without drawbacks and the case study approach has its pros and cons.However, its use is dependent upon the nature of the research. Case study analysis is believed to incorporate the bias of the researchers. This alarming fact implies a high possibility of any findings of the study being biased and case study analysis must be approached with care. However, case study analysis gives a more holistic view of the bigger picture and takes the eye close to details of similarities and differences from case to case. This approach is beneficial for solving current problems through understanding and applying findings from 
the past. Moreover, compared to econometric and related studies, case study analysis is a time and cost-effective method of research that yield useful data (Creswell \& Plano Clark, 2007).

This researcher will also take into account 'cross-sectional' studies considering the state of mind of the participants/respondents at a certain point in time; unlike the 'longitudinal' approach that focuses on changes in opinion overtime (Amy and Grauerholz,2012). This is the choice of research because the real need to solve the problem is the state of mind of patients at a certain point in time. However, where a longitudinal study is empirical and addresses the core issues of the research, it will be reviewed for the collection and analysis of the data.

The researcher will also include qualitative studies that consider the human perspective on the Recovery Model and medication adherence. Qualitative studies evaluate the motives and reasons for people's perspectives, beliefs, and behaviours and can find a better insight into people's lived experience (Amy and Grauerholz,2012).

It is further proposed that two data collection sources, primary and secondary, be used for collecting evidence and necessary literature on professionals and patients so that an environment is created where necessary insights can be taken into consideration for the use of data analysis, conclusions, and recommendations.

Lastly, it is the aim to create knowledge by using the proposed methodologies in order to make necessary recommendations that can change current practice; and help achieve the objective through the proposed aims of this research while answering the identified research questions.

\subsection{Population}

The population for this research is huge. It includes any and all of the professionals who are associated with the treatment of patients of any gender, age, religion, national or ethnic background. However, the patients are limited by their health and mental issues to those being targeted to solve the problem of non-adherence in a search for possible applications of the Recovery Model. This limitation serves to focus on the meaning of the case study.

\section{Results}

A total of 104 abstracts were identified for screening following the primary electronic search. This selection was further reducedbyscreening to take into consideration the four research questions. Those abstracts that were more appealingwith regard to the inclusion criteria and related to the research questions were selectedby this screening. Due to the fact that the research questions are interrelated and that the focus would be on the perspectives of patients and health providers, medication adherence,and policies on recovery,three major themes of interest emerged: the patient perspective on recovery, health care providers' perspective on recovery, and policies guiding recovery.A total of 70 articles fully addressed the inclusion criteria at this stage of screening of which 15 were finally randomly selected to address evidence validating recovery elements and medication adherence in mental health. Although they were selected randomly, the researcher briefly read through the introduction, identified the research design and considered the findings and conclusion before validating. During this last detailed screening, it became obvious that two themes rather than three would emerge. These includeclient-centred elements of recovery/medication adherence (under which sub-themes such as hope, social aspects of recovery, empowerment and shared decision making will be highlighted indiscriminately) and government policies guiding recovery.Ten governmental policies were selected as evidence, indicating that some countries within Europe advocate a Recovery Model as appropriate in providing care in the mental health sector.

\subsection{Client Centred Elements of Recovery/ medication adherence (summary table appendix 2).}

Mental health care planning can be defined as an iterative five-step process incorporating needs assessment, formulation, outcome and intervention planning, implementation and evaluation in light of the care received (Hall and Callaghan, 2008) This definition implies that the health professionals will take into account individual needs, collaboratewith the patients in exchanging information andin making decisions about their care.

In the final screening, the researcher had identified those elements of recovery mostly associated with the individual to include hope, empowerment and shared decision making. The social aspect of recovery will also be highlighted since these elements of recovery are functional when patients interact with the society, especially with individualssuch as friends, family and health professionals. These interactions can either enhance or hinder the patient's ability to seek help, have hope, develop agency and create a reason for living (Onken et al., 2002).

Marino (2015), May et al. (2015), Park and Chen(2016) and Bradshaw (2015) identified hope as a vital ingredient in recovery. Park and Chen (2016), in a systematic review, came to the conclusion that positive 
psychology is fundamental to creating a feeling in people that life is worth living and in understanding how they face adverse challenges and create experiences unique to their life. These findings conclude that hope is an important element that reinforces a patient's belief that recovery from mental illness is possible.

Bradshaw (2015), in a prospective study,found that hope and coping mechanisms are vital to recovery. The aim of the study was to bring to light the relevance of coping skills and hope as major facets of recovery and laid emphasis on how the levels of hope and coping skills interact. The findings also highlight the importance of family support in times of difficulty to a healthy recovery.

Marino (2015) maintains that hope, contribution and a sense of belonging are vital initial stages in social recovery. Thissame study reveals that once a patient begins to identify him or herself not in the light of the diagnosis, but as one also contributing to the society, it may bring about a sense of belongingness and a hope that recovery is possible.Similarly, a study carried out by May et al. (2015)shows that people with a comorbid anxiety disorder are driven by hope and agentic thinking towards recovery outcomes such as seeking treatment.

Aardoom (2014), in a qualitative study, addresses the use of an electronic source, a pro-recovery website called 'Proud2Bme as a way of sharing information amongst those with eating disorders. This e-Health initiative is based on the principle that when patients are well informed about their situation, they become more autonomous and may want to adhere to treatment and take responsibilities in their care.

Unlike the above mentioned studies highlighting positive aspects propelling recovery, there are other proponents of recovery model expressing varying views that are setbacks to patient recovery. These include Zhang et al. (2005), maintaining that through self-stigma and self-empowerment, a primal threat may have a detrimental effect on the recovery of a person with a mental health condition. He maintains that, at a point in time, those facing much primal threat may give in to the society's stigmatising attitude and internalise those attitudes. This then may lead to high levels of self-stigmatisation and consequently a poorer personal recovery. In addition, self-stigmatisation may further diminish a sense of active agency, leading to a poor recovery as a result of a reduction in an individual's engagement in proactive behaviours.Tan et al. (2015)further support these findings in a study where they found out that if family caregivers have negative feelings and are sensitive to the stigma surrounding the use of psychotropic drugs by relatives with mental health issues, such feelings and behaviour may be projected andbe imparted to the patientwhen giving the medication.

Newman et al. (2015) in their study on the experience expressed by service users with mental health issues, identify the following problems: a poor therapeutic relationshipthat denies the opportunity for the patient to confront staff in times of crisis, concerns of stigma preventing the patient from properly accessing the services as a result of shame, poor self-esteem and a lack of willingness to disclose information and, finally,not involving the service users in care planning.

In order to curb some of these recovery biases Williams et al. (2015), in a qualitative analysis, reveal that promoting social citizenship should be a core element in recovery-oriented social work interventions. They maintained that the focus should be on eradicating stigma, and building a social and psychological atmosphere in which those diagnosed with mental health issues will find meaning and hope in their lives. Tan et al. (2015) found that adherent patients have a higher inclination towards outpatient visits and adherence to psychotropic medication because they are provided with a better support system where various outpatient and community services are at their disposal.

This finding is supported by Handa et al,(2009) in a case study using a Continuing Day Treatment (CDC) programme in which the researchers explore the strength and interestof the service users, aiming at promoting recovery. In all four cases, it was proven that $\mathrm{CDC}$ is an essential recovery intervention in enhancing present levels of skills and functioning, developing self-esteem and self-awareness and the skills necessary for community living.

Conn et al (2016) in their studies reveal that interventions such as using cues and prompts for taking medication, for example, a notice on the refrigerator or making sure that the medication is kept close to where meals are eaten will be effective in enhancing adherence. They also found out that interventions that take into consideration the patient's daily routine and link administration of medication to such routines were effective in adherence. Similarly, Kauppi et al. (2015) in their study, emphasise that considering each individual's daily routine in planning treatment will improve adherence. They further found that respecting the patient's view and taking into account their experience of medication will increase the willingness to adhere to it.

Ghandi et al. (2014), in their study on medication adherence reveal, a significant correlation between work behaviour, self-esteem and medication adherence.They found that work can influence positively on medication adherence and self-esteem.

Studies carried out by, Ramdour et al.(2015) revealed thatthe three basic factors identified by health professionals whichcan improve on medication adherence include, a positive relationship with staff and family members, positive patient attitudes and patient insight into the need for the medication.

Younas et al. (2016), agreed to the fact that shared decision making and patient empowerment enhance adherence and recovery. 
Assessing the Use of Recovery Model for Medication Adherence on Mental Health Patients $-A$..

\subsection{Policies}

- Deutsche Gesellschaft für Psychiatric; (2006) Germany

- National Institute for Clinical Excellence (2002)the UK

- The Department of Health (2004)the UK

- The Nursing and Midwifery Council (2010)theUK

- Mental Health in England (NIMHE), (2005), Scottish Executive, (2006)

- Department of Health(2010) theUK

- Department of Health (2007)the UK

- Department of Health (2008)the UK

- Department of Health (2011)the UK

- Healthcare Commission (2008)the UK

all provide guidelines in their respective countries advocating a client-centred approach to delivering care in the mental health sector.

\section{Analysis and Application}

The purpose of this research was to understand the applicability, effectiveness and efficiency of the Recovery Model by applying it, and answering the research questions of research in an individual case. The following analysis should provide answers to each of the defined research questions, followed by a discussion that will highlight the integration of literature reviewed and personal clinical expertise of the researcher; as well as the preferences and values of the patient who is part of the independent case study. In other words, evidencebased practice, which was adopted, would be analysed for meaningful and applicable insights that were gauged from the integration of literature, clinical expertise, and patient preferences.

Shumway and Kimball (2012) defined hope as "A reawakening after despair" and the "Ability to expect with greater confidence."Hope is essential in recovery as the person experiencing mental health issues begins to develop confidence in living and constructs a pathway to encounter the challenges that come with living with psychiatric disabilities. Having this in mind it is logical that health professionals should endeavour to use care packages that will instill hope in their patients in clinical practice. Goal-directed thinking can be facilitated by the hope which, in a way, aligns with cognitive process. A positive way of thinking may further enhance the development of coping strategies and the patients accepting active participation in the rehabilitation plan (Park and Chen, 2016). The relationship between hope and recovery among people with mental health issues is established as evidence in some recent studies. A good example isa study carried out by Waynor et al. (2012), involving 74 participants in supported employment. The assessment revealed that higher hopes were related to fewer symptoms and hopelessness inclined towards severe symptoms.

However, in order to instil hope in patients, it is important that the health professionals themselves maintain attitudes that will bring about dignity and respect. Gray (2002) opines that the treatment outcomes and the patient's quality of life are both highly dependent on how the health professionals view those experiencing mental health issues.

In addition to hope, May et al. (2015) also introduced self-efficacy as an element that could lead to a goal related thinking.Bandura (2002) defines self-efficacy as the individual's perception of his or her ability to complete a specified task; including engaging in certain behaviours.

Hope, however, despitebeing perceived as a driving force to treatment and recovery could only be meaningful in the context of how the person experiencing mental health issues interacts with the immediate environment and society at large; whether those interactions improve or deter the establishment of hopefulness(Onken et al., 2002).

Marino (2015) further outlines communityparticipation, an occupation of valued social roles, the exercise of personalauthority and development of a positive self-identity as the main essentials for social recovery.In this study, all forty participants agree that, in their journey to recovery, these elements were essential in providing hope and acceptance of theirtreatment.

In self-concept, the participants express the view that, acceptance into society as individuals worthy to contribute and provide something to others brings hope and confidence in living. Some mentioned that they have regained their strength and confidence by involving themselves in doing things that were beyond their expectations. Previously, they had been trapped by their perceptions of being limited by their mental state and by the feeling that their condition would result in other people viewing them as different.

The participants felt that in order to gain social inclusion, they should be able to express themselves and that could be possible through the learning of new skills in social interaction while letting go of whatever negative feelings that come with living with mental health issues. Some individuals found that the use of coping strategies unique to them meant that they were able to let go the internalised identity implied by the diagnosis. 
The participants all felt a sense of belonging to a community that valued them for their competence while accepting their vulnerability. Such a community, according to the participants, would comprise of those who empathise with their experience and those they can build a relationship with;based on trust and mutual support.Similarly, in a case study carried out by Handaet al. (2009), Continuous Day Treatment (CDT)was essential as a recovery tool in enhancing present levels of skills and functioning, developing self-esteem and self-awareness and the skills necessary for community living through the exploration of individual strength and interest.

In Case one: Mr. X has been known to the service since the age of 14 and has a diagnosis of paranoid schizophrenia. Apart from auditory hallucinations, paranoid, delusional thinking and agitation, he has an extensive history of learning and behavioural problems, stealing food impulsively, and difficulties with integrating into the society.

On admission, an initial assessment and individualised care plan was done; emphasising his assets and needs and with a recovery directed approach.His bizarre behaviour and social isolation were addressed through redirecting his attention and interaction with staff members. Individual attention and a therapeutic relationship enhanced his improvement. Through modeling and mentoring, Mr. X's counselor had daily sessions with him to promote and teach more socially appropriate interactions. His mother was also involved in the process, directing the continuation of new skills learned whilst at home. His daily care package, consisted of individual and group counselling, daily morning assessments and structured exercises to redirect behaviours that are impulsive. Through repetitive redirection, hospitalisation was not required as Mr. X achieved more appropriate responses. He developed his ability to interact with others without anger, increased his involvement in recreational and social activities, and maintained a stable relationship with his mother. His dilapidating symptoms were treated with the use of psychotropic medication.

Case Two refers to patient Y: a 57-year-old man known to the service since the age of 19 . He has a chronic history of paranoid schizophrenia, verbally and physically threatening behaviour, being abusive to staff and nonadherence to his medication. He is at high risk of suicide, self-harming, harm to others, and self-neglect; refusing to engage in personal hygiene even when prompted. After an extensive history of hospitalization, he was finally referredto the CDT program.

Through CDT, the staff provided structured activities geared towards normalising his interaction with others, and his inappropriate and incoherent speech was addressed by focussing onhis expressed needs and reassurance. In addition to the CDT, he was provided with staff support and skills and knowledge of his medication that impacted on active participation in taking his medication. With the improvement of basic skills of living, Mr. Y was moved into asupervised residence in which the counsellor and other staff continue to maintain regular interaction; to identify progress and difficulties. In engaging Mr. Y in this program, the staff observed that there was a significant improvement in his stress management skills, fewer frequency outbursts of anger, and he was engaging more in managing his medication.

In all cases,including the cases of Mr. Z and Ms. L who were also experiencing severe and complex mental health issues, it was still proven that CDT was appropriate in managing even severe symptoms in schizophrenia, disruptive behaviour, social isolation and poor management of medication. In analysingthe qualitative study by Marino (2015), wherepatients reported their lived experiences, and in a case study by Handa, (2009) where patients were engaged in a CDT program, there was a commonality in that a client-centered approach became paramount in both cases. Identifying individual needs, initiating hope, empowering the clients by providing the skillsneeded, upholding their dignity, and social inclusion hasbeen useful in enhancing recovery and management of medication in both cases. To give more insight into this concept, the researcher will further make reference to some of the studies systematically reviewed. Ramdour et al. (2015) found that clinicians identified a positive relationship with staff and family members, positive patient attitudes and patient insight into the need for the medication were significant in medication adherence and overall recovery. May et al. (2015), Park and Chen (2016) and Bradshaw (2015) all came to the conclusion that hope is essential in enhancing patient recovery. Kauppi et al. (2015) supported the fact that when the patient's views are respected and the daily routine linked to the management of treatment plan, medication adherence will improve. In Aardoom (2014), the response from most of the participants in the studyseems to suggest that proud2Bme is promising in empowering those experiencing symptoms associated with eating disorders; helping them to have autonomy over their lives and the management of their condition. To a smaller extent, the study reveals empowering the patient through this medium will positively influence control and optimism over the future; increasing confidence in the treatment and a good therapeutic relationship with caregivers.

CDT programmes incorporate adherence to therapy. This therapy is flexible, patient-centred, and collaborative and a way of making clients adhere to medication. The objective of such therapy is to encourage patient and therapist to make joint decisions about medication. This may involve a regular one to one session with the patient to discuss issues pertinent to medication,including side effects and how the patient copes with 
them, engagement and assessing and rating the readiness to take the medication. Another dimension to recovery and medication adherence is empowering the individual to take some responsibility for their treatment. According to Drury and Reicher (2005), "Self-empowerment denotes confidence and an adaptive motivation to respond to the current condition with a sense of personal control and self-efficacy". Empowering a patient could be achieved through shared decision making in which he/she takes an active role in making decisions about the treatment plan. According to Younas et al. (2016),shared decision making is described by the NHS as "The conversation that happens between a patient and their healthcare professional to reach a healthcare choice together, where both parties consider what is important to the other when selecting treatment".

In a study carried out by Younas et al. (2016) on medication adherence, all the pharmacists involved in the study supported the use of shared decision making in psychotropic prescribing and agreed to the fact that shared decision making is a positive concept. However,a few pharmacists in this same study held the view that shared decision making is more a case of persuading patients to adhere to the prescribed medication rather than involving them in mutual decision making. They also held the view that the attitude of patients towards shared decision making varies. Whereas some may want to be involved in their treatment, others will prefer the clinicians to make decisions for them. However, the salient point here is that their choice is respected and they may feel dignified in that they at least have the right to make a decision despite their prevailing condition.

There are some governments all over the world considering the Recovery Model as a policy in enhancing medication adherence and in the overall care provided to patients in mental health services. This is reflected in recent treatment guidelines for schizophrenia suchas Deutsche Gesellschaft für Psychiatric, (2006); and National Institute for Clinical Excellence,(2002); all recommending shared decision making as a therapeutic process in engaging with service users during treatment. This aligns with the empirical findings that most patients believe that they should share equally in making decisions about their care (Hamann et al., 2010).

The Department of Health (2004) in the UK, identifies the "Ten Essential Shared Capabilities for Mental Health Practice" as the most significant developments in mental health education,similar to the elements of recovery. These include "Working in partnership, practicing ethically, respecting diversity, promoting recovery, Challenging inequality, Identifying people's needs and strength, providingservice user centered care, Personal development and learning, promoting safety and positive risk-taking". According to Stickley et al. (2016), this concept is similar tothe Recovery Competencies for New Zealand Mental Health Workers. The Nursing and Midwifery Council (2010) also seems to have incorporated most of these values into their Standards of Competence for Registered Nurses; mostly in the section dealing with the mental health nurse competencies.

The Australian Federal Governmenthas been operating a policy "Partners in Recovery", in the local health care regions since 2012 in order to provide efficient services to those with severe and complex mental health issues. The programme referenced recovery, focusing on providing individual needs in order for those with severe mental health problems to live a meaningful life, with or without symptoms (Smith-Merry \& Gillespie, 2016).

Mental Health in England (NIMHE)(2005), published "Guiding Statement to Recovery". This report was the basis for endorsing and recommending the use and application of the Recovery Model as a means of guidance for the mental health service provision as well as for public education. It can safely be assumed here that the guidance was realised by practitioners owing to its efficacy.

Review of Nursing in Scotland also recommended the use and application of the Recovery Model in the recovery approach for mental health nursing care and intervention,(Scottish Executive, 2006).This suggests that the Recovery Model has is liked and recommended by the higher authorities as well as by those involved in the field.

In England, the Department of Health (2007) and other healthcare policy documents (Healthcare Commission, 2008 and Department of Health, 2011) all advocate involving patients in the planning of their care and treatment. Policy developers have all accepted that this approach will improve mental health services by enhancing the quality of care and improving the culture within the service. In the future, the guidelines recommend that, following a mental health assessment, a care plan will be developed jointly by the healthcare professional, the patient and any other parties with a direct part to play in treatment. These changes in approach will enhance recovery.

Girard, et al. (2014)in a study on mental health issues in Marseille, France, addressed the cooperationbetween the police and the mental health outreach team responding to the clinical needs of homeless people with serious mental health disorders. It is a recovery effort to reach those who are isolated due to stigma and to empower them to have trust in care providers and to engage with the health services when the need arises. 


\subsection{Conclusion}

\section{Conclusion\& Recommendations for practice}

The main problem identified in this study was the non-adherence of patients towards the prescriptions and recommendations of the practitioners. The overall aim was to enable the researcher to conduct an independent case study; targeted and linked to this area of practice and aided by prior research findings. The literature reviewyielded many ways oftackling the problem but the Recovery Model proved to be both efficacious and to give meaningful results. The findings of the literature review, combined with the patient preference and clinical expertise, enabled effective application of the Recovery Model. In addition, the researcher was able to derive recommendations that would help this area of practice with the application of the Recovery Model on independent cases.

It became apparent that the Recovery Model is essential for both medication adherence and the overall treatment process. Patients and health professionals share the opinion that using the Recovery Model will bring a better result. Also, there are health policies in most countries supporting the fact that recovery should be the basis of offering care at all levels in the health sector. These policies also provide guidelinesfor achieving medication adherence using recovery.

However,the literaturereview had some limitations in that whereas most of the data sources provided details of the effect of the Recovery Model on overall treatment and controlof mental health symptoms, few gave specific details on medication adherence.

\subsection{Recommendations}

Having conducted an extensive literature review and applied the findings to an independent case, recommendations in response to the original question are:The Recovery Model is a step by step format that maximizes effectiveness and efficiency if these steps are followed as recommended.

Choice, dignity, and autonomy are important elementsaiding the initiation of a relationship between the practitioner and the patient andstrengthening this relationship during later stages of treatment. More research should be conducted to see how these elements will directly influence medication adherence.

There are clear sets of guidance; provided by NHS and MHRS, and built on the basis of many past experiences. These should be followed both in order to comply with the law and to enhance the efficacy of treatment.It is imperative to incorporate patient preferences in order to elevate and improve the relationship. Sometimes efficiency can be compromised for the robustness of this relationship.An effective doctor/patient relationship leads to increasing quality of life and manages to enhance the growth opportunities for the patient and aids more rapid recovery.

It is imperative to deal with specific cases with respect and with reference to previous similar cases. This approach enhances the overall process as each patient has a distinct identity and possesses unique characteristics that result in an individual set of requirements for effective treatment.

\subsection{Areas for Further Study}

There is vast scope for further research into this aspect of treatment some of which could be covered as follows: Firstly, the Recovery Model and evidence-based practice can be applicable in areas other than the field of mental health. There is a great deal of literature available pertaining to the application of recovery model.

Secondly, the consolidation of different case studies from around the world would help enhance the practical implications of the Recovery Model. Many sources suggest lawful application of the elements of the Recovery Model worldwide and specifically in the USA and Australia.

Finally, analysis of the law pertaining to the application of the Recovery Model could result in modification of the law in some countries where it constitutes a barrier to progress.

\section{References}

[1]. Aardoom,J. Alexandra, E., Dingemans, A., Boogaard, L.H and Van Furth, E.F. (2014). Internet and patient empowerment in individuals with symptoms of an eating disorder: A cross-sectional investigation of a pro-recovery focused e-community. Eating Behaviors 15 (2014) 350-356

[2]. Bandura, A. (1977). Self-efficacy: Toward a unifying theory of behavioural change. Psychological Review, 84(2), 191-215.

[3]. Barber, M.E. (2012). Recovery as the new medical model for psychiatry. Psychiatric Services.

[4]. Bradshaw, S., Shumway, S.T., Wang, E.W., Harris KS, Smith, D.B \& Austin-Robillard, H. (2015). Hope, Readiness, and Coping in Family Recovery from Addiction, Journal of Groups in Addiction \& Recovery, 10:4, 313-336

[5]. Bryman, A. (2015). Social research methods. Oxford university press.

[6]. Bollini, P., Tibaldi,G., Testa, C. \& Munizza, C. (2004). 'Understanding treatment adherence in affective disorders: a qualitative study.' J Psychiatr Ment Health Nurs. 11(6):668-74.

[7]. Burns, N. and Grove, S.K., (2007) Understanding Nursing Research: Building an Evidence-based Practice: Saunders ElsevierChronister, J., Chou, C.C. and Liao, H.Y. (2013). The role of stigma coping and social support in mediating 
Assessing the Use of Recovery Model for Medication Adherence on Mental Health Patients $-A$..

the effect of societal stigma on internalized stigma, mental health recovery, and quality of life among people with serious mental illness. Journal of Community Psychology, 41(5), pp.582-600.

[8]. Conn, V.S., Todd, M. Ruppar,T.M Enriquez, M. andCooper, P.(2016). Medication adherence interventions that target subjects with adherence problems: Systematic review and meta-analysis. Administrative Pharmacy 12: 218-246

[9]. Coughlan M, Cronin P, Ryan F (2007). Step-by-step guide to critiquing research. Part 1: qualitative research. 16(11): 658-63

[10]. Creswell, J. \& Clark, P. (2007). 'Designing and conducting mixed methods research.' Thousand Oaks, CA: Sage.

[11]. Delamater, A.M (2006). 'Improving Patient Adherence'. Clinical Diabetes 24:71-77.

[12]. Deegan, P.E. and Drake, R.E. (2006). Shared decision making and medication management in the recovery process. Psychiatric Services, 57(11), pp.1636-1639.

[13]. Department of Health (2004). The Ten Essential Shared Capabilities a Framework for the Whole of the Mental Health Workforce. Available athttp://www.iapt.nhs.uk/silo/files/10-essential-shared-capabilities.pdf. Accessed on the $10^{\text {th }}$.octorber.2016.

[14]. Department of Health (2007).Putting People First: A Shared Vision and Commitment to the Transformation of Adult Social Care. Department of Health London.

[15]. Department of Health (2008). Refocusing the Care Programme Approach: Policy and Positive Practice Guidance. Department of Health, London.

[16]. Department of Health (2010). Equity and excellence: liberating the NHS. Norwich:The Stationery Office Ltd.

[17]. Department of Health (2011). No Health without Mental Health: A Cross-Government Mental Health Outcomes Strategy for People of All Ages. Department of Health, London.

[18]. Deutsche Gesellschaft für Psychiatrie PuND (2006). S3-Praxisleitlinien Psychiatrie und Psychotherapie. Bd 1. Behandlungsleitlinien Schizophrenie. Steinkopff, Darmstadt

[19]. DiMatteo, M.R., Giordani, P.J., Lepper, H.S. and Croghan,T.W.(2002). Patient adherence and medical treatment outcomes: a meta-analysis. Med Care; 40:794-811.

[20]. Drury, J.andSteve,R.(2005).Explaining enduring empowerment:A comparative study of collective action and psychological outcomes:European Journal of Social Psychology:35,35-58

[21]. Gandhi, S., Pavalur R., Thanapal S., Parathasarathy,N., Desai, G. and Bhola, P. (2014). Medication adherence, work performance and self-esteem among psychiatric patients attending psychosocial rehabilitation services at Bangalore, India. Indian Journal of Psychological Medicine. 36.4 (October-December 2014): p392.

[22]. Girard, V., Bonin, J.P, Tinland, A., Farnarier, C., Pelletier J.F., Delphin,M., Rowe, M.,and Simeoni M.C.(2014). Mental health outreach and street policing in the downtown of a large French city: International Journal of Law and Psychiatry 37: 376-382.

[23]. Gould E., and Mitty E.(2010). Medication Adherence is a Partnership, Medication Compliance is Not. Geriatric Nursing, 31:290-298

[24]. Gray, A. J. (2002). Stigma in psychiatry. Journal of the Royal Society ofMedicine, 95(2), 72-76.

[25]. Grauerholz, E. and Donley, A.M, (2012). Research Methods. Infobase Publishing, New York.

[26]. Hall, J. \& Callaghan, P. (2008). Developments in managing mental health care: a review of the literature. Issues in Mental Health Nursing 29, 1245-1272.

[27]. Hamann, J., Mendel, R., Schebitz, M., Reiter, S., Bühner, M. and Cohen, R., (2010). CanPsychiatrists and neurologists predict their patients' participation preferences? TheJournal of Nervous and Mental Disease, 198: 309311.

[28]. Handa K, Grace J, Trigoboff E, Annalett D, Watson T, Poulose MC, Muzaffar T, Noyes FL, Kabatt A, Cushman S, Antonelli M, Baxter-Banks G and Newcomer D. (2009). Continuing Day Treatment Programs Promote Recovery in Schizophrenia: A Case-based Study. Psychiatry (Edgemont);6(4):32-36

[29]. Healthcare Commission (2008). The Pathway to Recovery: A Review of NHS Acute Inpatient Mental Health Services. Healthcare Commission, London

[30]. Irish Mental Health Commission (2005) A vision for a recovery model in Irish Mental HealthServices.Dublin: Mental HealthCommission.

[31]. Ho, P.M., Bryson, C.L. and Rumfeld, J.S. (2009). 'Medication Adherence: Its Importance in Cardiovascular Outcomes': 119(23):3028-35

[32]. Jackson, C., Eliasson, C., Barber, N. \& Weinman,T.(2014).Applying COM-B to medication adherence :A suggested framework for research and intervention. The European Health Psychologist. 16: 7-34

[33]. Kauppi,Hätönen H., Adams C.E., \& Valimaki. M., (2015). Perceptions of treatment adherence among people with mental health problems and healthcare professionals. Journal of Advanced Nursing 71(4), 777-788.

[34]. Marder, S.R.(1998). Facilitating compliance with antipsychotic medication. Journal of Clinical Psychiatry, 59(Suppl3):21-25

[35]. Marino, C.K (2015). To belong, contribute, and hope: first stage development of a measure of social recovery, Journal of Mental Health, 24:2, 68-72

[36]. May EM, Hunter BA, Ferrari J, Noel N and Jason LA (2015) Hope and Abstinence Self-Efficacy: Positive Predictors of Negative Affect in Substance Abuse Recovery Community Ment Health J. 51:695-700

[37]. National Institute for Clinical Excellence (2002). Guidance on the use of newer (atypical) antipsychotic drugs for the treatment of schizophrenia. London: National Institute for Clinical Excellence

[38]. Newman, D., O'Reilly, P., Lee, S.H,. and Kennedy, P. (2015).Mental health service users' experiences of mentalhealth care: an integrative literature review Journal of Psychiatric and Mental Health Nursing, 22, 171-182 
Assessing the Use of Recovery Model for Medication Adherence on Mental Health Patients $-A$..

[39]. NICE(2009) Clinical guidelines 76: medicines adherence involving patients in decisions about prescribed medications and supporting adherence:http://www.nice.org.uk/guidance/cg76/chapter/introduction Accessed 6 Oct. 2016.

[40]. NIMHE(2005).'Guiding Statement of Recovery' Available online at: http://Studymore.org.uk/nimhere.pdf. Accessed: $10^{\text {th }}$ March 2016.

[41]. Nursing and Midwifery Council (2010). Standards for Competence for Registered Nurses(London).

[42]. Onken,S.J.,Dumont,J.M.,Ridgway,P., Dornan,D.H.\&Ralph,R.O.(2002).Mental Health Recovery: What Helps and What Hinders? A National Research Project for theDevelopment of Recovery Facilitating System Performance Indicators. Phase One Research Report: A National Study of Consumer Perspectives on What Helps and Hinders Recovery. Alexandria VA: National Technical Assistance Center for State Mental Health Planning.

[43]. Park,J. Roy, K. Chen, RK(2016).Positive Psychology and Hope as Means to Recovery from Mental Illness. Journal of Applied Rehabilitation Counselling: 47 (2)34-42

[44]. Pipaarva, K.G, Buch, J.G andChandrani, K.V (2011). Analysis of Adverse Drug Reactions of Atypical Antipsychotic Drugs in Psychiatry OPD.Indian J Psychol Med.; 33(2):153-7

[45]. Ramdour, S., Duxbury, J.A, Becket, B. and Wilson, S. (2015). A cross-sectional observational study of healthcare professional views of factors affecting teenage adherence with antipsychotic medication. Journal of Psychiatric and Mental Health Nursing, 22, 491-501.

[46]. Roberts, G. \& Wolfson, P. (2004). The rediscovery of recovery: open to all. Advances in Psychiatric Treatment, 10, $37-49$.

[47]. Shumway, S. T.\& Kimball, T. G. (2012). Six essentials to achieve lasting recovery.Center City, MN: Hazelden.

[48]. Smith-Merry, J.\& Gillespie, J. (2016). Embodying policy-makingin mental health: the implementation of Partners in Recovery, Health Sociology Review, 25:2,187-201,

[49]. Stanniland, C., and Taylor, D. (2002). Tolerability of atypical antipsychotics. Drug Safety, 22:195-214.

[50]. Scottish Executive (2006) Rights, Relationships and Recovery: The Report of the National Review of Mental Health Nursing in Scotland.

[51]. Stein, B.D., Kogan, J.N., Mihalyo, M.J., Schuster, J., Deegan, P.E., Sorbero, M.J. and Drake, R.E., (2013). Use of a computerized medication shared decision making tool in community mental health settings: impact on psychotropic medication adherence. Community mental health journal, 49(2), pp.185-192.

[52]. Stickley,T., Higgins, A., Oonagh Meade., Sitvast, J., Doyle, L., Ellilä, H.,Jormfeldt, H., Keogh, B., Lahti, M., Skärsäter, I.,Vuokila-Oikkonen, P. and Kilkku, N. (2016). From the rhetoric to the real: A critical review of how the concepts of recovery and social inclusion may inform mental health nurse advancedlevel curricula - The eMenthe project. Nurse Education Today 37 (2016) 155-163

[53]. Tan,X., Marshall,V.D, Balkrishnan,R., Patel,I.,Chang,J. R., Erickson,R.S. (2015). Psychotropic Medication Adherence among Community-BasedIndividuals with Developmental Disabilities and Mental Illness, Journal of Mental HealthResearch in Intellectual Disabilities, 8:1, 1-22,

[54]. Valenstein M., Blow F.C, Copeland L.A, McCarthy J.F, Zeber, J.E, Gillon L., Bingham C.R andStavenger, T. (2004). Poor antipsychotic adherence among patients with schizophrenia: medication and patient factors. Schizophr Bull. 30(2):255-64.

[55]. Velligan, D.I., Weiden, P.J. \&Sajatovic, M. (2010) Strategies for addressing adherence problems in patients with serious and persistent mental illness: recommendations from the Expert Consensus Guidelines. Journal of Psychiatric Practice 16 (5) 306-324

[56]. Waynor, W. R., Gao, N., Dolce, J. N., Haytas, L. A., \& Reilly, A. (2012). The relationship between hope and symptoms. Psychiatric Re-habilitation Journal, 35(4), 345-348.

[57]. Williams, C.C., Almeida, M. and Knyahnytska, Y. (2015). Towards a Biopsychosociopolitical Frame for Recovery in the Context of Mental Illness. British Journal of Social Work 45, Supplement 1, i9-i26

[58]. Younas, M., Bradley, E.,Holmes, N., Sud,D., Ian D. and Maidment, I.D.(2016).Mental health pharmacists views on shared decision-making for antipsychotics in serious mental illness: Int. Journal of Clinical Pharmacy 38:11911199

[59]. Zhang, R., Mak, W. W. S., \& Chan, R. C. H. (2016). Perceived Primal Threat of Mental Illness and Recovery: The Mediating Role of Self-Stigma and Self-Empowerment. American

[60]. Journal of Orthopsychiatry. Advance online publication. http://dx.doi.org/10.1037/ort0000202

\section{Appendices}

Appendix One

The following table will differentiate the inclusion criteria and exclusion criteria of the study:

\begin{tabular}{|c|c|c|c|}
\hline & Population & Intervention & Outcome/Impact \\
\hline Inclusion & $\begin{array}{l}\text { - Professionals and Patients from both } \\
\text { gender and all age groups. } \\
\text { - Patients must be 'mental health' related; } \\
\text { regardless of religion, ethnicity, country etc. } \\
\text { - Organisations that are working to establish } \\
\text { similar objective(s) and aims. }\end{array}$ & $\begin{array}{l}\text { - Any knowledge or experiment or } \\
\text { case that has incorporated the } \\
\text { objective of recovery for mental } \\
\text { health patients; more importantly } \\
\text { the recovery model itself. } \\
\text { - Government and concerned } \\
\text { organisations' rules and } \\
\text { regulations. }\end{array}$ & $\begin{array}{l}\text { Applicability of Recovery } \\
\text { Model together with the } \\
\text { implication, regulations and } \\
\text { supporting literature. Moreover, } \\
\text { the impact on the relationship } \\
\text { between professionals and } \\
\text { patients to eliminate non- } \\
\text { adherence and non-compliance. }\end{array}$ \\
\hline
\end{tabular}


Assessing the Use of Recovery Model for Medication Adherence on Mental Health Patients - A ..

\begin{tabular}{|c|c|c|c|}
\hline Exclusion & $\begin{array}{l}\text { - Studies that haven't incorporated 'mental } \\
\text { health' patients. } \\
\text { - Studies that haven't incorporated the view } \\
\text { of professionals. } \\
\text { - Organisation that are not working on } \\
\text { similar lines/domain. }\end{array}$ & $\begin{array}{l}\text { - Any knowledge or experiment or } \\
\text { case that has not incorporated the } \\
\text { end result as the application of } \\
\text { recovery model. } \\
\text { Rules and Regulations not } \\
\text { addressing recovery in the domain } \\
\text { of mental health. }\end{array}$ & $\begin{array}{l}\text { Outcomes would be in the form } \\
\text { of irrelevant information with } \\
\text { respect to the aims and objective } \\
\text { of the current research. }\end{array}$ \\
\hline
\end{tabular}

\section{Appendix Two}

Evidence

Client Centred Elements of Care(Recovery Elements)

\begin{tabular}{|c|c|c|c|}
\hline Aothur/ Year & Study Design & Patient Population & Key Findings \\
\hline 1.Tan et al (2015) & $\begin{array}{l}\text { Retrospective } \\
\text { Study }\end{array}$ & $\begin{array}{l}\text { Mental } \\
\text { health/developmental } \\
\text { disability. }\end{array}$ & $\begin{array}{l}0.8 \leq \text { PDC } \leq 1=\text { Adherence } \\
\text { Positive association between psychotropic medication } \\
\text { adherence and impatient visits may be indicative of better } \\
\text { support system, better outpatient and community service to } \\
\text { meet health needs. }\end{array}$ \\
\hline $\begin{array}{l}\text { 2.Park and Chen } \\
(2016)\end{array}$ & $\begin{array}{l}\text { Integrative } \\
\text { Review }\end{array}$ & Mental Health Patients & $\begin{array}{l}\text { Main review was in satisfaction, that positive psychology, } \\
\text { hope, empowerment, } \\
\text { and positive attitude in combination of active role in } \\
\text { society will enhance recovery. }\end{array}$ \\
\hline 3.Ramdour et al & $\begin{array}{l}\text { Cross sectional } \\
\text { survey }\end{array}$ & $\begin{array}{l}\text { Mental health staff } \\
\mathrm{N}=60\end{array}$ & $\begin{array}{l}\text { Using Likert Scale } \\
\text { Medication will make them better } 93 \% \\
\text { Rapport with staff } 85 \% \\
\text { Medication will prevent relapse } 83 \% \\
\text { Views of Staff } 78 \% \\
\text { Important To be in control of their life } 70 \% \\
\text { To be in control of decisions about medication } 68 \% \\
\text { Would be admitted to hospital if they didn't take } \\
\text { medication } 68 \% \\
\text { Medication will help them achieve their goals } 68 \% \\
\text { Pressure from family } 67 \% \\
\text { Views of family } 65 \% \\
\text { Medication will help them think more clearly } 63 \% \text {. } \\
\text { Concluded that, positive attitude and staff rapport, family } \\
\text { support, and patient insight will enhance psychotropic } \\
\text { adherence in first episode psychosis. }\end{array}$ \\
\hline 4.Newman (2005) & $\begin{array}{l}\text { Integrative } \\
\text { Review }\end{array}$ & $\begin{array}{l}\mathrm{N}=34 \quad \text { papers on } \\
\text { mental health patients }\end{array}$ & $\begin{array}{l}\text { Therapeutic relationship, self-esteem, and involving } \\
\text { patients in care planning will enhance recovery }\end{array}$ \\
\hline $\begin{array}{l}\text { 5.Williams et al. } \\
(2015),\end{array}$ & Mixed Methods & \begin{tabular}{lr}
\multicolumn{2}{l}{ Mental health patients. } \\
$\mathrm{N}=65 \quad$ quantitative \\
analysis. \\
$\mathrm{N}=20$ & \\
analysis & Qualitative
\end{tabular} & $\begin{array}{l}\text { Holistic approach will enhance recovery. } \\
\text { Biomedical: Diagnose and evaluating the usefulness of } \\
\text { medication. } \\
\text { Psychological: Finding purpose, hope and meaning in life. } \\
\text { Social: Social citizenship }\end{array}$ \\
\hline $\begin{array}{l}\text { 6. Kauppi et } \\
\text { al.(2015) }\end{array}$ & $\begin{array}{l}\text { Descriptive } \\
\text { Qualitative }\end{array}$ & $\begin{array}{l}\mathrm{N}=19 \text { Patients } \\
\mathrm{N}=42 \quad \text { Health } \\
\text { Professions. }\end{array}$ & $\begin{array}{l}\text { Involving patients and needs in care planning will enhance } \\
\text { medication adherence. Considering patient daily routine } \\
\text { and respecting their views will enhance adherence. }\end{array}$ \\
\hline 7.Conn et al.(2016) & $\begin{array}{l}\text { Systematic } \\
\text { review/meta- } \\
\text { analysis }\end{array}$ & $\begin{array}{l}\mathrm{N}=57 \quad \text { journals on } \\
\text { mental health patients }\end{array}$ & $\begin{array}{l}\text { Incorporating patient's daily routine in medication } \\
\text { management will increase adherence. Prompts or cues as a } \\
\text { source of support and empowerment will improve on } \\
\text { medication adherence. }\end{array}$ \\
\hline
\end{tabular}


Assessing the Use of Recovery Model for Medication Adherence on Mental Health Patients - A ..

\begin{tabular}{|c|c|c|c|}
\hline 8. Marino, $(2015)$ & Qualitative Study & $\mathrm{N}=41$ Patients & $\begin{array}{l}\text { The desire to belong, contribute and have } \\
\text { hope for the future is essential in } \\
\text { recovery. }\end{array}$ \\
\hline $\begin{array}{l}\text { 9. Aardoom et } \\
\text { al.(2015) }\end{array}$ & $\begin{array}{l}\text { Cross-sectional } \\
\text { Research }\end{array}$ & $\begin{array}{l}\mathrm{N}=311 \text { Patient with eating } \\
\text { disorder. }\end{array}$ & $\begin{array}{l}\text { Empowering patients will enhance } \\
\text { treatment adherence and recovery. }\end{array}$ \\
\hline 10. May et al(2015) & Longitudinal study & $\begin{array}{l}\text { Substance } \text { abuse patients } \\
\text { comorbid } \\
\text { depression. }\end{array}$ & $\begin{array}{l}\text { Hope, especially agency thinking will } \\
\text { enhance recovery. }\end{array}$ \\
\hline 11. Zhang et al.(2015) & Qualitative study & $\mathrm{N}=376$ mental health patients & $\begin{array}{l}\text { High Cronbach alpha scores for the } \\
\text { following variables, } \\
\text { Empowerment } .93 \text {, living condition } .86 \text {, } \\
\text { social relationship .87, evaluation of } \\
\text { self.91 and } .76 \text { for work as essential for } \\
\text { recovery. }\end{array}$ \\
\hline $\begin{array}{l}\text { 12.Bradshaw et al } \\
\text { (201 }\end{array}$ & Prospective Study & $\begin{array}{l}\text { Families of those with mental } \\
\text { health issues }\end{array}$ & $\begin{array}{l}\text { Hope, coping skills and readiness to } \\
\text { change are essential in family recovery }\end{array}$ \\
\hline 13.Handa et al(2009) & Case study & $\begin{array}{l}\mathrm{N}=4 \text { patients with severe } \\
\text { mental health issues }\end{array}$ & $\begin{array}{l}\text { Client-centred approach enhances } \\
\text { recovery and medication adherence. }\end{array}$ \\
\hline $\begin{array}{l}\text { 14.Younas } \\
\text { (2016) }\end{array}$ & $\begin{array}{l}\text { Exploratory } \\
\text { Qualitative Study }\end{array}$ & $\begin{array}{l}\mathrm{N}=13 \quad \text { Mental } \quad \text { Health } \\
\text { Pharmacist. }\end{array}$ & $\begin{array}{l}\text { Shared decision making empowers and } \\
\text { improve on medication adherence. }\end{array}$ \\
\hline
\end{tabular}

\begin{tabular}{|l|l|l|l|l|}
\hline 15.Ghandi et al. (2014) & $\begin{array}{l}\text { Quantitative, descriptive, } \\
\text { correlational research } \\
\text { design }\end{array}$ & $\begin{array}{l}\mathrm{N}=60 \quad \text { Mental Health } \\
\text { Patients }\end{array}$ & $\begin{array}{l}\text { Correlation between medication } \\
\text { adherence, work performance and self- } \\
\text { esteem among the subjects }(n=60), P> \\
0.05, \mathrm{NS} .\end{array}$ \\
\hline
\end{tabular}

